\title{
Echocardiographic evaluation of verapamil in Friedreich's ataxia
}

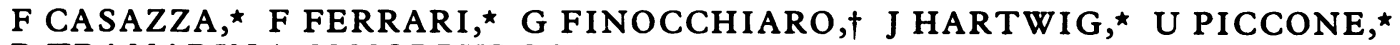 \\ R TRAMARIN, * MMORPURGO* \\ From the ${ }^{\star}$ Department of Cardiology, San Carlo Hospital, and $\dagger$ Besta Neurological Institute, Milan, Italy
}

SUMMARY Nine patients with hypertrophic cardiomyopathy associated with Friedreich's ataxia were treated with the calcium antagonist verapamil, which is known to reduce myocardial hypertrophy and improve diastolic function in patients with idiopathic hypertrophic cardiomyopathy. Daily oral doses of $7 \mathrm{mg} / \mathrm{kg}$ were given for a mean (SD) of 24 (8) months. M mode echocardiography performed at the start of the study and at the end of follow up showed no significant difference between the treated group and an untreated control group of nine patients. Verapamil produced no changes in left ventricular wall thickness, mass index, left ventricular internal diameter, fractional shortening, peak normalised lengthening rate, peak rate of septal and posterior wall thinning, and time from minimum ventricular cavity dimension to mitral valve opening.

Myocardial calcium overload has been suggested as a cause of cardiac disease in Friedreich's ataxia; however, verapamil had no beneficial effect on these patients with established myocardial hypertrophy.

Left ventricular hypertrophy (usually concentric and non-obstructive) has been found in $38 \%$ to $67 \%$ of patients with Friedreich's ataxia. ${ }^{1-3}$ In a series of 18 cases our own group found echocardiographic evidence of concentric left ventricular hypertrophy in $39 \%$ of cases and asymmetric (non-obstructive) hypertrophy in $33 \%{ }^{4}$ St John Sutton et al found reduced diastolic function in most of their patients with Friedreich's ataxia. ${ }^{5}$

Calcium antagonists have been effective in other forms of hypertrophic cardiomyopathy. Kaltenbach et al gave oral verapamil $(480 \mathrm{mg}$ daily) for more than a year to patients with obstructive hypertrophic cardiomyopathy. ${ }^{6}$ They found that QRS voltage, heart volume (determined radiologically), and left ventricular mass (determined haemodynamically) were reduced. Hirzel et al confirmed these findings ${ }^{7}$; as did Spicer et al in children. ${ }^{8}$ Verapamil has also been reported to improve left ventricle relaxation and filling in adults and children with hypertrophic cardiomyopathy.$^{8-10}$

Other evidence encourages the use of calcium an-

Requests for reprints to Professor Mario Morpurgo, Via Boccaccio 24, 20123 Milan, Italy.

Accepted for publication 3 December 1985 tagonists for cardiomyopathy. Sanchez-Casis et al described granular calcium and iron deposits in degenerate myocardial fibres in a patient with Friedreich's ataxia. ${ }^{11}$ Lamarche et al, however, did not confirm this finding in an electron microscope study of three cases. ${ }^{12}$ It has been suggested but not confirmed that the cardiomyopathy associated with Friedreich's ataxia may be the result of defective calcium transport through cell membranes with subsequent accumulation in the fibres. ${ }^{13-14}$ These reports prompted us to study the long term effect of verapamil on cardiomyopathy in patients with Friedreich's ataxia.

\section{Patients and methods}

Thirteen patients with Friedreich's ataxia diagnosed by Geoffroy's criteria ${ }^{15}$ entered the trial. In all of them left ventricular hypertrophy of various grades of severity was seen on M mode echocardiography, and none of them had any contraindications to long term calcium antagonist treatment. They all gave their informed consent. Two patients dropped out within two months because of hypotension, another abandoned treatment, and a fourth did not report for follow up examinations after 7 months. The nine remaining patients (group 1) (5 male and 4 female), 
Table 1 Echocardiographic variables used to assess effect of verapamil treatment on heart muscle

\begin{tabular}{ll}
\hline Variable & Abbreviation \\
\hline (1) Interventricular septum thickness & IVSTh \\
(2) Left ventricular posterior wall thickness & LVPWTh \\
(3) IVSTh/LVPWTh ratio & - \\
(4) Left ventricular end diastolic diameter & LVEDD \\
(5) Left ventricular end systolic diameter & LVESD \\
(6) Left ventricular mass index & LV mass index \\
(7) Left ventricular fractional shortening & FS\% \\
(8) Left atrium:aorta ratio & LA:AO \\
(9) Time from minimum left ventricular cavity & \\
& dimension to the onset of mitral \\
(10) Palve opening & LVESD-MVO \\
(11) Peak rate of septal thinning & Lng rate \\
(12) Peak rate of posterior wall thinning & dSd/dt \\
\hline
\end{tabular}

were aged from 10 to 34 years (mean age (SD) 21.9 (7.5)), with body surfaces between 1.05 and $1.8 \mathrm{~m}^{2}$ (mean (SD) area $1.43(0.27)$ ). Another nine patients with the same condition (group 2) served as controls. There were 6 male and 3 female patients aged from 10 to 36 years old (mean (SD) age $20 \cdot 3(8 \cdot 1)$ ), with body surfaces between 0.9 and $1.8 \mathrm{~m}^{2}$ (mean (SD) area $1.45(0.24))$. Patients had cardiological examinations every three months for 13 to 37 months in group 1 (mean (SD) 24 (8.4) months) and 10 to 49 months in group 2 (mean 24 (SD) 13 months). Age, body surface area, and length of follow up were similar in the two groups. Echocardiographic findings of groups 1 and 2 were compared with those of 25 normal subjects (group 3) of similar mean (SD) age (20.6 (9.7) years) and body surface area (1.44 $\left.(0 \cdot 15) \mathrm{m}^{2}\right)$. Patients took verapamil $(7 \mathrm{mg} / \mathrm{kg}$ daily) as two or three separate oral doses. Venous blood samples were taken from seven of the nine patients within four to six hours of a dose of verapamil and were assayed for unchanged drug and metabolites (norverapamil $\mathrm{D}_{617}$ to $\mathrm{D}_{620}$ ). Blood concentrations (mean (SD) $128(118) \mathrm{ng} / \mathrm{ml}$ ) were within therapeutic range (41 to $327 \mathrm{ng} / \mathrm{ml}$ ).

Table 1 shows echocardiographic variables that we used to assess the effect of verapamil treatment on the heart muscle. Each patient was examined by $M$ mode echocardiography on at least three occasions. Echocardiograms were obtained with a commercially available machine equipped with a $0.5 \mathrm{~cm}$ transducer, ultrasound frequency $2.25 \mathrm{MHz}$, connected to a paper printout unit (chart speed 25 or $50 \mathrm{~mm} / \mathrm{sec}$ ), and an electrocardiogram was recorded simultaneously. All echocardiographic examinations were conducted by the same cardiologist who followed the recommendations of the Workshop of the European Society of Cardiology, ${ }^{16}$ and paid special attention to the left and right endocardium of the interventricular septum and posterior wall of the left ventricle. Tracing reproducibility was ensured by consistent use of the same echocardiographic window with the patient in the same position. Left ventricular mass was calculated by the Devereux equation and Penn's convention. ${ }^{17}$ Left ventricular volume was calculated by the cube formula. All tracings were technically adequate for calculation of variables 1 to 8 (Table 1 ).

Left ventricular diastolic function was assessed from a digitised $M$ mode echocardiogram recorded at $50 \mathrm{~mm} / \mathrm{s}$ chart speed. Six of nine echocardiograms in group 1 and seven of nine in group 2 were suitable for computer analysis. For each case we digitised three consecutive cardiac cycles with clearly identifiable septal endocardial and posterior wall endocardial echoes. The $M$ mode cursor was positioned over the left ventricle to provide best imaging of the interventricular septum, posterior wall of the left ventricle, and separation of mitral valve leaflets. The point of mitral valve opening was identified. Digital conversion was done with a hand operated graphic tablet (Hewlett-Packard 9111A); digital data were processed by a Hewlett-Packard 1000 computer system that gives instantaneous plots of left ventricular internal dimension, septal and posterior wall thickness, and the rate at which they are changing. Variables 9 to 12 (Table 1) were calculated by computer analysis. Peak normalised lengthening

Table 2 Statistical comparison (Kramer test) of echocardiographic variables in patients with Friedreich's ataxia treated with verapamil (group 1), untreated patients (group 2), and healthy subjects (group 3)

\begin{tabular}{|c|c|c|c|c|c|c|c|c|c|}
\hline Variable & Group 1 vs & Group 3 & $p$ & Group 2 vs & Group 3 & $p$ & Group 1 vs & Group 2 & $p$ \\
\hline $\begin{array}{l}\text { IVSTh (mm) } \\
\text { LVPWTh (mm) } \\
\text { IVS/LVPW } \\
\text { LVEDD (mm) } \\
\text { LVESD (mm) } \\
\text { LV mass index }\left(\mathrm{g} / \mathrm{m}^{2}\right) \\
\text { FS\% } \\
\text { LA/AO }\end{array}$ & $\begin{array}{c}11 \cdot 1(1.4) \\
10.9(1.6 \\
1.0(0.2) \\
38.4(5.3) \\
25.2(5 \cdot 7) \\
111.9(26) \\
34.1(8.3) \\
1.1(0.1)\end{array}$ & $\begin{array}{c}6.5(1 \cdot 0) \\
6 \cdot 1(1 \cdot 2) \\
1.1(0.2) \\
44.8(4 \cdot 2) \\
26.9(3 \cdot 4) \\
62.5(16) \\
39.7(4 \cdot 8) \\
1.1(0 \cdot 1)\end{array}$ & $\begin{array}{l}<0.01 \\
<0.01 \\
\text { NS } \\
<0.01 \\
\text { NS } \\
<0.01 \\
<0.05 \\
\text { NS }\end{array}$ & $\begin{array}{r}10.2(1.3) \\
10.0(0.8) \\
0.9(0.1) \\
41.5(4.6) \\
26.5(4.5) \\
112.8(18) \\
36.2(7.6) \\
1.1(0.2)\end{array}$ & $\begin{array}{r}6.5(1 \cdot 0) \\
6 \cdot 1(1 \cdot 2) \\
1.1(0.2) \\
44.8(4 \cdot 2) \\
26.9(3.4) \\
62.5(16) \\
39.7(4 \cdot 8) \\
1.1(0.1)\end{array}$ & $\begin{array}{l}<0.01 \\
<0.01 \\
\text { NS } \\
\text { NS } \\
\text { NS } \\
<0.01 \\
\text { NS } \\
\text { NS }\end{array}$ & $\begin{array}{c}11.1(1.4) \\
10.9(1.6) \\
1.0(0.2) \\
38.4(5.3) \\
25.2(5.7) \\
111.9(26) \\
34.1(8.3) \\
1.1(0.1)\end{array}$ & $\begin{array}{r}10.2(1.3) \\
10.0(0.8) \\
0.9(0.1) \\
41.5(4.6) \\
26.5(4.5) \\
112.8(18) \\
36.2(7.6) \\
1.1(0.2)\end{array}$ & $\begin{array}{l}\text { NS } \\
\text { NS } \\
\text { NS } \\
\text { NS } \\
\text { NS } \\
\text { NS } \\
\text { NS } \\
\text { NS }\end{array}$ \\
\hline $\begin{array}{l}\text { Body surface } \\
\text { area }\left(\mathrm{m}^{2}\right)\end{array}$ & $1.4(0.3)$ & $1.4(0.1)$ & NS & $1.4(0.3)$ & $1.4(0.1)$ & NS & $1.4(0.3)$ & $1.4(0.3)$ & NS \\
\hline
\end{tabular}

See Table 1 for abbreviations. 
Table 3 Statistical comparison (Kramer test) of echocardiographic variables in left ventricular diastolic function and relaxation in patients with Friedreich's ataxia treated with verapamil (group 1), untreated patients (group 2), and healthy subjects (group 3)

\begin{tabular}{|c|c|c|c|c|c|c|c|c|c|c|c|c|}
\hline Variable & Group 1 & vs & Group 3 & $p$ & Group 2 & vs & Group 3 & $p$ & Group 1 & vs & Group 2 & $p$ \\
\hline $\begin{array}{l}\text { LVESD-MVO (ms) } \\
\text { Lng rate }\left(\mathrm{s}^{-1}\right) \\
\mathrm{dSd} / \mathrm{dt}(\mathrm{cm} / \mathrm{s}) \\
\mathrm{dWd} / \mathrm{dt}(\mathrm{cm} / \mathrm{s})\end{array}$ & $\begin{array}{l}57(26) \\
3.7(0.6) \\
4.3(1.4) \\
6.7(1.9)\end{array}$ & & $\begin{array}{l}55(27) \\
5 \cdot 0(1 \cdot 6) \\
6 \cdot 8(2 \cdot 3) \\
12(3 \cdot 3)\end{array}$ & $\begin{array}{l}\text { NS } \\
\text { NS } \\
<0.05 \\
<0.01\end{array}$ & $\begin{array}{l}28(39) \\
4 \cdot 0(0.9) \\
4.5(1 \cdot 6) \\
7 \cdot 2(3 \cdot 2)\end{array}$ & & $\begin{array}{l}55(27) \\
5 \cdot 0(1 \cdot 6) \\
6 \cdot 8(2 \cdot 3) \\
12(3 \cdot 3)\end{array}$ & $\begin{array}{l}\text { NS } \\
\text { NS } \\
<0.05 \\
<0.01\end{array}$ & $\begin{array}{l}57(26) \\
3.7(0.6) \\
4.3(1.4) \\
6.7(1.9)\end{array}$ & & $\begin{array}{l}28(39) \\
4.0(0.9) \\
4.5(1.6) \\
7.2(3.2)\end{array}$ & $\begin{array}{l}\text { NS } \\
\text { NS } \\
\text { NS } \\
\text { NS }\end{array}$ \\
\hline
\end{tabular}

See Table 1 for abbreviations.

rate and peak rate of septal and posterior wall thinning were used to assess diastolic function. ${ }^{18}$ Time from minimum left ventricular cavity dimension to onset of mitral valve opening was used as an index of left ventricular relaxation. We did not measure the isovolumic relaxation time (that is the interval between the second heart sound and mitral valve opening) because in some cases an accompanying phonocardiogram was not available; also, this interval has been reported to be an unreliable indicator of ventricular relaxation in patients with hypertrophic cardiomyopathy. ${ }^{19}$

We used the Kramer test ${ }^{20}$ and covariance analysis $^{21}$ for statistical analysis; the former is suitable for comparison of means from groups of unequal sizes and the latter for adjusting values obtained at the end of follow up so that the influence of differences between the initial means for the two groups is eliminated.

\section{Results}

Tables 2 and 3 show the echocardiographic data from patients with Friedreich's ataxia treated with verapamil (group 1), data from similar patients not receiving treatment (group 2), and data from normal subjects (group 3).

Patients with Friedreich's ataxia (groups 1 and 2) had significantly $(p<0.01)$ thicker interventricular septal and posterior left ventricular walls. They also had significantly $(p<0.01)$ higher left ventricular mass indices and significantly $(p<0.01)$ slower peak rates of posterior wall thinning. Peak rates of septal thinning were significantly $(\mathrm{p}<0.05)$ slower in patients with Friedreich's ataxia than in normal subjects. The end diastolic diameter of the left ventricle was significantly smaller in patients of group 1 than in group 3, but there was no significant difference between groups 2 and 3 . The left ventricular fractional shortening was significantly less in patients in group 1 (but not in patients in group 2 ) than in group 3 (p<0.05).

There were no differences between groups for time from minimum left ventricular cavity dimension to onset of mitral valve opening or for peak lengthening rates. Tables 4 and 5 summarise the initial and final echocardiographic findings obtained in patients of groups 1 and 2. Palpitation in one patient and recurrent headache in another abated while they were on verapamil. None of the patients developed evidence of heart failure during long term verapamil treatment.

\section{Discussion}

Our results are at variance with those reported by other workers who used similar doses of verapamil to treat patients with hypertrophic cardiomyopathy. .5822 We found that long term treatment with verapamil of patients with cardiomyopathy as-

Table 4 Statistical comparison (covariance analysis ${ }^{\star}$ ) of echocardiographic variables at the beginning and at the end of follow up in patients who were treated with verapamil and those who were not

\begin{tabular}{|c|c|c|c|c|c|c|}
\hline \multirow[t]{2}{*}{ Variable } & \multicolumn{3}{|c|}{ Before verapamil } & \multicolumn{3}{|c|}{ After verapamil } \\
\hline & Group 1 & vs & Group 2 & Group 1 & vs & Group 2 \\
\hline $\begin{array}{l}\text { IVSTh }(\mathrm{mm}) \\
\text { LVPWTh }(\mathrm{mm}) \\
\text { IVS/LVPW } \\
\text { LVEDD (mm) } \\
\text { LVESD (mm) } \\
\text { LV mass index }\left(\mathrm{g} / \mathrm{m}^{2}\right) \\
\text { FS\% } \\
\text { LA/AO }\end{array}$ & $\begin{array}{r}11 \cdot 1(1 \cdot 4) \\
10 \cdot 9(1 \cdot 6) \\
1.0(0 \cdot 2) \\
38 \cdot 4(5 \cdot 3) \\
25 \cdot 2(5 \cdot 7) \\
111.9(26) \\
34 \cdot 1(8 \cdot 3) \\
1.2(0 \cdot 1)\end{array}$ & & $\begin{array}{r}10 \cdot 2(1.3) \\
10.0(0.8) \\
0.9(0 \cdot 1) \\
41.5(4.6) \\
26.5(4.5) \\
112.8(18) \\
36.2(7.6) \\
1.1(0.2)\end{array}$ & $\begin{array}{c}11.1(1.8) \\
11.1(1.9) \\
1.0(0.1) \\
40.4(5.0) \\
26.5(5.1) \\
124.3(41) \\
35.1(5.7) \\
1.1(0.1)\end{array}$ & & $\begin{array}{r}10 \cdot 3(1 \cdot 3) \\
9 \cdot 4(1 \cdot 1) \\
1 \cdot 1(0 \cdot 1) \\
42 \cdot 5(6 \cdot 5) \\
27 \cdot 0(6 \cdot 4) \\
108 \cdot 1(17) \\
36 \cdot 8(7 \cdot 6) \\
1 \cdot 1(0 \cdot 2)\end{array}$ \\
\hline
\end{tabular}

${ }^{\star}$ None of the variables was significantly different.

See Table 1 for abbreviations. 
Table 5 Statistical comparison (covariance analysis ${ }^{\star}$ ) of echocardiographic variables of left ventricular diastolic function and relaxation at the beginning and at the end of follow up in patients treated with verapamil (group 1) and those who were not (group 2)

\begin{tabular}{|c|c|c|c|c|c|c|}
\hline \multirow[t]{2}{*}{ Variable } & \multicolumn{3}{|c|}{ Before verapamil } & \multicolumn{3}{|c|}{ After verapamil } \\
\hline & Group 1 & vs & Group 2 & Group 1 & vs & Group 2 \\
\hline $\begin{array}{l}\text { LVESD-MVO (ms) } \\
\text { Lng rate }\left(\mathrm{s}^{-1}\right) \\
\mathrm{dSd} / \mathrm{dt}(\mathrm{cm} / \mathrm{s}) \\
\mathrm{dWd} / \mathrm{dt}(\mathrm{cm} / \mathrm{s})\end{array}$ & $\begin{array}{l}57(26) \\
3 \cdot 7(0 \cdot 6) \\
4 \cdot 3(1 \cdot 4) \\
6 \cdot 7(1.9)\end{array}$ & & $\begin{array}{l}28(39) \\
4.0(0.9) \\
4.5(1 \cdot 6) \\
7 \cdot 2(3 \cdot 2)\end{array}$ & $\begin{array}{l}44(14) \\
5 \cdot 1(1 \cdot 5) \\
5 \cdot 7(2 \cdot 6) \\
9 \cdot 8(4 \cdot 5)\end{array}$ & & $\begin{array}{l}31(33) \\
4 \cdot 1(1 \cdot 6) \\
4 \cdot 1(1 \cdot 2) \\
6 \cdot 8(2 \cdot 7)\end{array}$ \\
\hline
\end{tabular}

\#None of the variables was significantly different.

See Table 1 for abbreviations.

sociated with Friedreich's ataxia produced no detectable difference by echocardiography between treated and untreated patients after mean follow up of two years. Our findings do, however, accord with those of Rosing et al who did not see any significant reduction of septal or posterior wall thickness in the left ventricle of 31 patients treated by long term administration of verapamil and followed up for at least one year. ${ }^{23}$ The reduction of left ventricular thickness reported by Kaltenbach et al, by Kuhn et $a l$, and by Spicèr was $<2 \mathrm{~mm}$ and was sometimes only of borderline significance. ${ }^{6822}$

Our results do not support the hypothesis that intramyocardial calcium accumulation is an important factor in the pathogenesis of cardiac disease in Friedreich's ataxia. Although the hypothesis rests on apparently good experimental evidence, the fact remains that verapamil did not reduce established myocardial hypertrophy. The role of calcium accumulation in the pathogenesis of myocardial hypertrophy in patients with Friedreich's ataxia can probably only be established by a study in which verapamil is given early in the course of disease, when neurological and cardiac signs and symptoms are just beginning to appear-that is, before myocardial cells are replaced by fibrotic tissue. ${ }^{924}$

Our data on basal diastolic function accord broadly with those reported by St John Sutton et al in a study of seven patients with Friedreich's ataxia. ${ }^{5}$ All patients with hypertrophic cardiomyopathy (groups 1 and 2) had a highly significant reduction of the posterior wall thinning peak rate and a significant reduction in septal thinning rate compared with normal subjects. The peak rate of left ventricular lenthening, on the other hand, was not significantly reduced (in St John Sutton's series this variable was slightly less than normal values in two of seven cases). Unlike St John Sutton et al we did not find that the time from minimum left ventricular cavity size to onset of mitral valve opening was significantly increased.

We found that oral verapamil had no beneficial effects in group 1, not even on the diastolic indices of left ventricular function. This finding is seldom referred to in published reports, and only then in patients with hypertrophic cardiomyopathy other than Friedreich's, and also chiefly in connection with studies of the short term effects of the drug. Even in this limited area, the results of various studies are not in complete accord. ${ }^{92526}$

In conclusion, long term oral treatment with verapamil at high doses was readily tolerated by all our patients. In particular, there was no deterioration of left ventricular systolic function or evidence of heart failure. Verapamil, a calcium antagonist, did not reduce left ventricular wall thickness, possibly because interstitial fibrosis in these patients with Friedreich's ataxia was already advanced. Left ventricular diastolic function was not significantly improved by long term verapamil treatment.

In our opinion routine verapamil treatment is not justified in symptom free patients who have Friedreich's ataxia complicated by hypertrophic cardiomyopathy. Alone or in association with other drugs, however, verapamil might be useful in the treatment of supraventricular tachyarrhythmia in selected cases.

We thank Mrs Loredana Parinello for the statistical analysis, and Dr R Padrini for the blood verapamil assays.

\section{References}

1 Gottdiener JS, Hawley RJ, Maron BJ, Bertorini TF, Engle WF. Characteristics of cardiac hypertrophy in Friedreich's ataxia. Am Heart $\mathcal{f}$ 1982; 103: 525-31.

2 Pasternac A, Krol R, Petitclerc R, Harvey C, Andermann E, Barbeau A. Hypertrophic cardiomyopathy in Friedreich's ataxia: symmetric or asymmetric? Can $\mathcal{F}$ Neurol Sci 1980; 7: 379-82.

3 Tainturier C, Komajda M, Nenna A, Grosgogeat Y, 
Busquet M, Evans J. Les atteintes cardiaques des maladies de Friedreich: intérêt des investigations cardiologiques non sanglantes. Med Interne 1983; 4: 73-81.

4 Beulcke G, Bottoni R, Casazza F, Uziel G, Morpurgo $M$. Aspects cardiologiques de l'hérédoataxie du type Friedreich. Arch Mal Cour 1982; 75: 583-92.

5 St John Sutton MG, Olukotun AY, Tajik AJ, Lovett JL, Giuliani ER. Left ventricular function in Friedreich's ataxia. An echocardiographic study. Br Heart $\mathcal{f}$ 1980; 44: 309-16.

6 Kaltenbach M, Hopf R, Kober G, Bussmann W-D, Keller M, Petersen Y. Treatment of hypertrophic obstructive cardiomyopathy with verapamil. Br Heart $\mathcal{f}$ 1979; 42: 35-42.

7 Hirzel HO, Troesch MP, Jenni R, Krayenbuehl HP. Effects of verapamil on ventricular wall thickness of patients with hypertrophic cardiomyopathy. In: Kaltenbach M, Epstein SE, eds. Hypertrophic cardiomyopathy. Berlin and Heidelberg: SpringerVerlag, 1982: 203-13.

8 Spicer RL, Rocchini AP, Crowley DC, Rosenthal A. Chronic verapamil therapy in pediatric and young adult patients with hypertrophic cardiomyopathy. Am $\mathcal{~ C a r - ~}$ diol 1984; 53: 1614-9:

9 Hanrath P, Mathey DG, Kremer P, Sonntag F, Bleifeld $W$. Effect of verapamil on left ventricular isovolumic relaxation time and regional left ventricular filling in hypertrophic cardiomyopathy. Am $\mathcal{f}$ Cardiol 1980; 45: 1258-64.

10 Bonow RO, Rosing DR, Bacharach SL, et al. Effect of verapamil on left ventricular systolic function and diastolic filling in patients with hypertrophic cardiomyopathy. Circulation 1981; 64: 787-96.

11 Sanchez-Casis G, Cote M, Barbeau A. Pathology of the heart in Friedreich's ataxia: review of the literature and report of one case. Can $\mathcal{F}$ Neurol Sci 1976; 3: 349-54.

12 Lamarche JB, Cote $M$, Lemieux $B$. The cardiomyopathy of Friedreich's ataxia: morphological observations in three cases. Can $\mathcal{F}$ Neurol Sci 1980; 7: 389-96.

13 Huxtable RJ. Cardiac pharmacology and cardiomyopathy in Friedreich's ataxia. Can $\mathfrak{f}$ Neurol Sci 1978; 5: 83-91.

14 Barbeau A. Friedreich's ataxia 1979: an overview. Can f Neurol Sci 1979; 6: 311-9.

15 Geoffroy G, Barbeau A, Breton G, et al. Clinical de- scription and roentgenologic evolution of patients with Friedreich's ataxia. Can $\mathcal{f}$ Neurol Sci 1976; 3: 279-86...

16 Echocardiography Working Group of the European Society of Cardiology. Raccomandazioni per la stan- $\stackrel{\oplus}{+}$ dardizzazione delle misure sugli ecocardiogrammi $\mathrm{M}$ mode. G Ital Cardiol 1979; 9: 220-2.

17 Devereux RB, Reichek N. Echocardiographic determination of left ventricular mass in man. Circulation 1977; 55: 613-8.

18 St John Sutton MG, Tajik AJ, Gibson DG, Brown के DG, Seward JB, Giuliani AR. Echocardiographic $\overrightarrow{0}$ assessment of left ventricular filling and septal and posterior wall dynamics in idiopathic hypertrophic $\vec{\omega}$ subaortic stenosis. Circulation 1978; 57: 512-20.

19 Gamble WH, Shaver JA, Alvares RF, Salerni R, Reddy PS. A critical appraisal of diastolic time interval as a $\mathrm{G}$ measure of relaxation in left ventricular hypertrophy. $\rightarrow$ Circulation 1983; 68: 76-87.

20 Kramer CJ. Extension of multiple range tests to group means with unequal numbers of replications. Biometrics 음 1956; 12: 307-12.

21 Bradley HE. The analysis of covariance and alternatives. I New York: John Wiley and Sons, 1980.

22 Kuhn H, Thelen U, Leuner C, Kohler E, Bluschke V, Loogen F. Long-term verapamil treatment in patients $\vec{\emptyset}$ with hypertrophic nonobstructive cardiomyopathy. In: o Kaltenbach M, Epstein SE, eds. Hypertrophic cardiomyopathy. Berlin and Heidelberg: Springer-Verlag, 1982: 214-24.

23 Rosing DR, Condit JR, Maron BJ, et al. Verapamil therapy: a new approach to the pharmacological treat- o ment of hypertrophic cardiomyopathy: III. Effect of $\unrhd$ long-term administration. Am $\mathcal{f}$ Cardiol 1981; 48: $\overrightarrow{\overrightarrow{0}}$ 546-53.

24 Hewer RL. The heart in Friedreich's ataxia. Br Heart f 1969; 31: 5-14.

25 Ten Cate FJ, Serruys PW, May S, Roelandt J. Effects of short-term verapamil on left ventricular relaxation and filling dynamics measured by a combined $\frac{2}{2}$ hemodynamic-ultrasonic technique in patients with hypertrophic cardiomyopathy. Circulation 1983; 68: 1274-9.

26 Bonow RO, Frederick TM, Bacharach SL, et al. Atrial systole and left ventricular filling in hypertrophic cardiomyopathy: effect of verapamil. Am $\mathcal{F}$ Cardiol 1983; 51: 1386-91. 